\title{
Relocation of Earthquake Hypocenter in The Flores Region Using Hypo71
}

\author{
Regolinda Maneno ${ }^{1}$, Bagus Jaya Santosa ${ }^{1}$ and Gazali Rachman ${ }^{2}$
}

\begin{abstract}
Flores is one of the seismically high activity zones of Indonesia region as a consequence of Indo-Australian plate subduction under the Eurasian plate. Tectonic earthquakes required to be studied because in large magnitude it can bring disaster. Therefore the precise of hypocenter determination needs to be done. In this study, hypocenter relocation is done by Single Event Determination method using hypo71. The data used are earthquake event data in Flores area which has magnitude > 4 SR at period between January 2010 and March 2018 obtained from BMKG catalog. Hypo71 requires data of arrival time of $P$ and $S$ waves at the recorder station. The arrival time of $P$ and $S$ waves data at each station is obtained by picking $P$ and $S$ waves using SeisGram2k70. The results showed that the source of the earthquake experienced a change of position both horizontally and vertically. In the vertical direction of hypocenter earthquake changes in the distance between $0.02-89.61 \mathrm{~km}$, while in the horizontal direction the hypocenter of the earthquake changes in the distance of 1.11 - $71.11 \mathrm{~km}$. After relocation, the hypocenter of the earthquake distributed along the Back Arc Trust in the northern island of Flores. Hypocenter relocation using hypo71 yields a small residual between the observation time and calculation time denoted by $\mathrm{RMS}$ $<1$.
\end{abstract}

Keywords—Flores, Hypocenter Relocation, Hypo71

\section{INTRODUCTION}

$I$ ndonesia located at the junction of three major tectonic plates (Eurasian Plate which is relatively moving south, the Indo-Australian Plate which is relatively moving north, and the Pacific Plate which is relatively moving toward the southwest) can form a subduction zone, thrust at the boundary of the plates and became the main area causing the spread of earthquakes in Indonesia. Flores Island is one of several Indonesian islands belonging to the Pacific Ring of Fire and shows high tectonic activity [1]. Flores thrust zone, a back-arc thrust extends from northern Flores passing Bali to NTB is one of the triggers of earthquake activity in Flores Region. According to the historical data, the area of Flores is potentially a tectonic earthquake that could provide a tsunami. However, seismic research in the Flores region is still rare. The distribution of earthquake events in Flores Region and its suburbs in 2010 to 2017 is mapped in Figure 1. The red color indicates earthquake at shallow depth $(0-100 \mathrm{~km})$, yellow color shows earthquake at intermediate depth $(100-300 \mathrm{~km})$ and green color shows earthquake at very depth $(>300 \mathrm{~km})$. The distribution earthquakes on Flores Island are dominated by the deep earthquakes as a result of the Indo-Australian plate subsidence. A very deep earthquake predominantly occurs in the Northern part of Flores associated with Flores Thrust Zone.

\footnotetext{
${ }^{1}$ Regolinda Maneno and Bagus Jaya Santosa are with Physics Department, Insitut Teknologi Sepuluh Nopember, Keputih, Sukolilo, Surabaya 60111, Indonesia. E-mail: regolindamaneno24@gmail.com.

${ }^{2}$ Gazali Rachman is with Physics Education Department, Faculty of Teacher Training and Education, Universitas Patimura, Jl. Ir. M Putuhena, Kampus Poka, Ambon, Maluku 97233, Indonesia.
}

Based on the earthquake hypocenter one can know the type of earthquake, the actual location of the earthquake origin, and other parameters which can further be used as a reference for determining the appropriate earthquake disaster mitigation. For that purpose accurate seismic location determination is important. Single Event Determination (SED), Joint Hypocenter Determination (JHD) and Double Difference (DD) are some methods for earthquake hypocenter relocation. We propose, in this paper to relocate hypocenter using SED method. SED method uses the theory and principles of the Geiger method through an iteration process using the least square optimization (the least squares principle).

Review an earthquake occurrence at a certain hypocenter $(x, y, z)$. The wave arrival time of the hypocenter observed at the $-i$ station with position $\left(x_{i}, y_{i}, z_{i}\right)$ is $\tau_{i}$. Then the wave arrival time from the source to the receiving station is calculated by means of a trial solution as $t_{i}$. The difference in the time of observation with the time of calculation is called the residual which can be written in the following equation:

$$
r_{i} \equiv \tau_{i}-t_{i}
$$

Calculation travel times of waves can be determined using the $1 \mathrm{D}$ velocity model but travel time is not a linear function to the hypocenter ( $d t, d x, d y, d z$ ) parameter. Nonlinearity makes it difficult for the inversion process to get a good hypocenter. Problems can be changed to linear by assuming that the residual is small enough so that Equation (1) can be written in Taylor's expansion as follows:

$$
r_{i}=d t+\frac{\partial t_{i}}{\partial x} d x+\frac{\partial t_{i}}{\partial y} d y+\frac{\partial t_{i}}{\partial z} d z+e_{i}
$$


The solution of the Geiger method for inversion problems so that the model obtained close to the results of observations (small residuals) is the least square method, namely by minimizing the number of squares of the error value.

$$
\sum e_{i}^{2}=\operatorname{minimum}
$$

The number of squares of the error value can be minimized by finding the optimum value from Equation (2), namely by taking the derivative of the function to an unknown independent variable which is zero. By conditioning Equation (3) to Equation (2), then 4 normal equations are obtained as follows:

$$
\begin{aligned}
& n d t+\sum \mathrm{a}_{i} d x+\sum b_{i} d y+\sum c_{i} d z=\sum r_{i} \\
& \sum \mathrm{a}_{i} d t+\sum a_{i}^{2} d x+\sum a_{i} b_{i} d y+\sum a_{i} c_{i} d z=\sum a_{i} r_{i} \\
& \sum b_{i} d t+\sum a_{i} b_{i} d x+\sum b_{i}^{2} d y+\sum b_{i} c_{i} d z=\sum b_{i} r_{i} \\
& \sum c_{i} d t+\sum a_{i} c_{i} d x+\sum b_{i} c_{i} d y+\sum c_{i}^{2} d z=\sum c_{i} r_{i} \\
& \text { with } a_{i} \equiv \frac{\partial t_{i}}{\partial x} ; b_{i} \equiv \frac{\partial t_{i}}{\partial y} ; c_{i} \equiv \frac{\partial t_{i}}{\partial z}
\end{aligned}
$$

Equation (4) is a linear equation that contains the relationship of model parameters with data that can be written in the following matrix relationship:

$$
[J]^{T}[J] \Delta m=[J]^{T} \Delta d
$$

with a Jacobian matrix of size $\mathrm{n} \times 4$ containing partial residual derivative data earthquake travel time from hypocenter guesses to each observer station. $n$ is the number of stations and 4 represents the hypocenter location (position and origin time). $\Delta m$ is a model parameter in the form of four variables to be sought and $\Delta d$ is observational data in the form of residual data when the earthquake wave arrives with size $\mathrm{n} \times 1$.

Equation (5) is often not easily solved because the matrix is ill-conditioned. The solution from Hypo71 to find model parameters is by stepwise regression. Equation (2) shows the residual as a function $d t, d x, d y$, and $d z$. For each search the hypocenter value becomes (xo $+d x$, yo $+d y$, zo $+\mathrm{dz}$ ) and the origin time becomes (to $+\mathrm{dt}$ ). The hypocenter value and new origin time obtained is a better solution than before. Calculation of the travel time of the wave continues through an iteration until the minimum residual value is obtained. If a small residual value is obtained then it is assumed that the velocity model has represented the actual state and the arrival time reading is correct or it can be estimated that the hypocenter value obtained is correct [2].

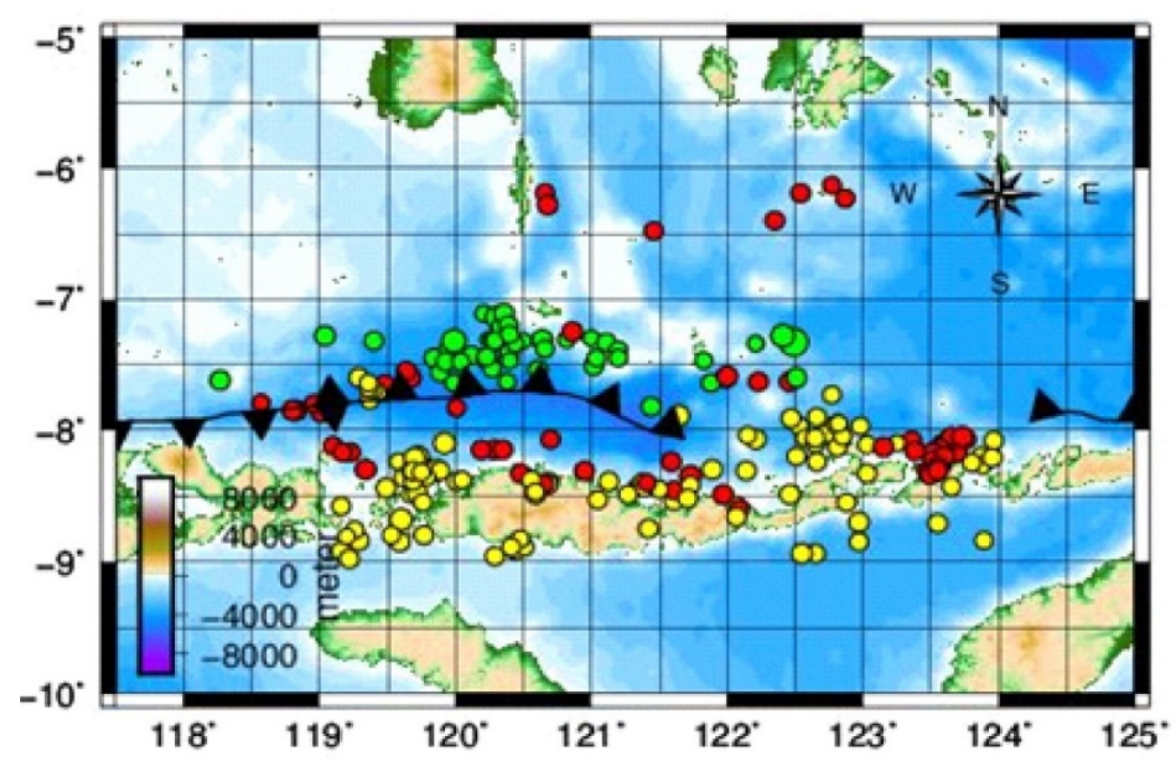

Figure 1. Map of the earthquake epicenter in Flores Region (2010-2018)

\section{METHOD}

This research uses 210 earthquake events downloaded from the catalog data at http://www.webdc.eu/webdc3 [3]. The selected earthquake data are the earthquakes occurring in the Flores region and its surroundings with a magnitude larger than 4.0 SR at the latitude position coordinates between -5.15 to 10.090 and longitude between 118.720 to 124.990 on periods between January 2010 and March 2018.
We use 14 stations that record earthquake events in Flores. JrdSeedVer0.10.1.jar is used to convert the *seed data format to *SAC. It produces 3 file components in each recording station, ie, $\mathrm{BHE}, \mathrm{BHN}$, and $\mathrm{BHZ}$. BHZ used for picking $\mathrm{P}$ wave and BHN/BHS used for picking $\mathrm{S}$ wave. Waves picking is done manually by using SeisGram2k70 to get the arrival time of $\mathrm{P}$ and $\mathrm{S}$ waves as shown in Figure 2. Seisgram2k70 software displays earthquake waves in the form of electrical voltage signals. 


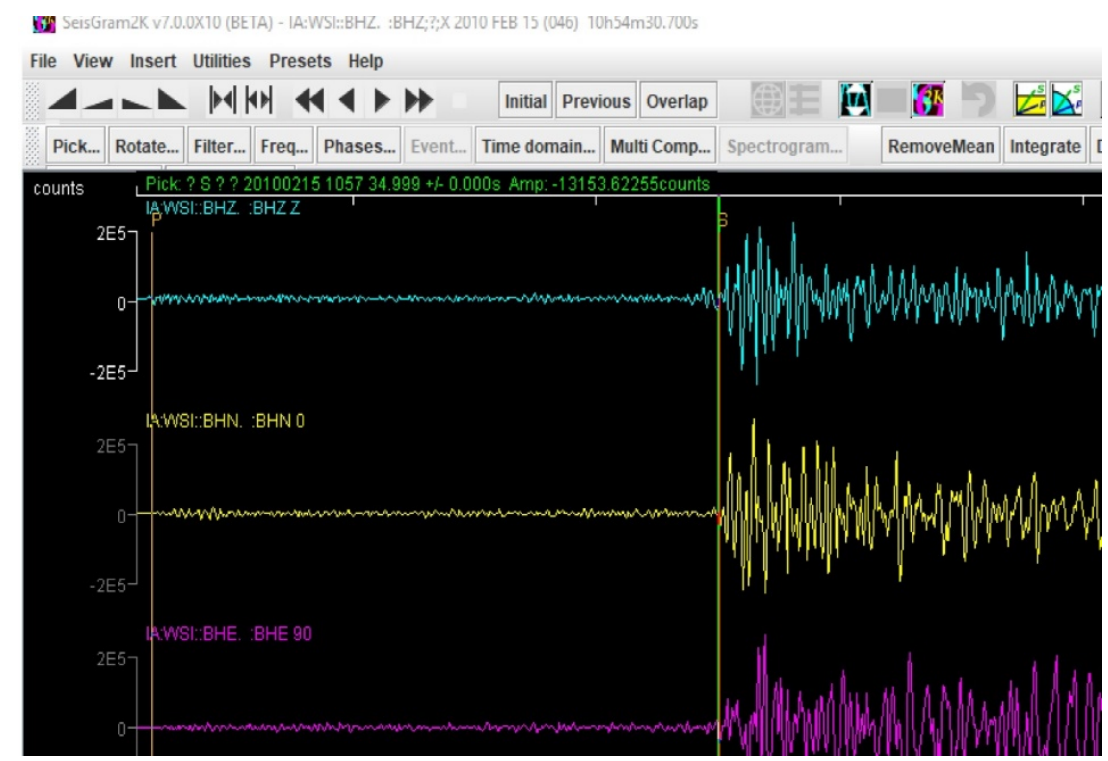

Figure 2. Waves picking using SeisGram2k70.

\section{A. Relocation of earthquake hypocenter}

Hypocenter relocation is a process to correct the hypocenter which is provided by webdc. We use the single event determination (SED) method through hypo71 software. The data used as input is the arrival time data of $\mathrm{P}$ and $\mathrm{S}$ waves obtained from picking wave, station position, and the 1D reference velocity model. The 1D reference velocity model used is a combination model of Santosa and Haslinger for a depth of 0 to $40 \mathrm{~km}$ while for depths over $40 \mathrm{~km}$ using the AK135 model as shown in Table 1. Input data is done in Hypo71.INP then the data will be executed by Hypo71exe. The output of hypo71 are a new value of hypocenter, ie, position and origin time, RMS, and the quality of the hypocenter determination which is showed in the hypo71.PUN and Hypo71.PRT files. The results of the hypocenter relocation are illustrated using the Generic Mapping Tool and compared to the Webdc-provided hypocenter.

TABLE 1.

THE REFERENCE MODEL VP AND VS, COMBINATION SANTOSA AND

\begin{tabular}{ccc}
\multicolumn{3}{c}{ HASLINGER MODEL AND AK135 MODEL. } \\
\hline \hline Depth (Km) & Vp (Km/s) & Vs (Km/s) \\
\hline 0 & 2.31 & 1.30 \\
1.0 & 4.27 & 2.40 \\
2.0 & 5.52 & 3.10 \\
5.0 & 6.23 & 3.50 \\
16.0 & 6.41 & 3.60 \\
33.0 & 6.70 & 4.70 \\
40.0 & 7.80 & 4.76 \\
100.0 & 8.00 & 4.57 \\
225.0 & 8.40 & 4.80 \\
325.0 & 8.60 & 4.91 \\
425.0 & 9.30 & 5.31 \\
460.0 & 9.52 & 5.60 \\
510.0 & 9.69 & 5.70 \\
610.0 & 10.00 & 5.88 \\
\hline \hline
\end{tabular}

\section{RESULT AND DISCUSSION}

\section{A. Relocation of earthquake hypocenter}

Hypocenter generated by hypo71 and Webdc are shown in Figure 3. The results of this study is that the hypocenter experienced a change of position both horizontally and vertically. In the vertical direction of hypocenter earthquake changes in the distance between 0.02 - $89.61 \mathrm{~km}$, while in the horizontal direction the hypocenter of the earthquake changes in the distance of $1.11-71.11 \mathrm{~km}$.

The hypocenter position is illustrated also in 3D as shown in Figure 4. The image shows the hypocenter distribution of depth. The results show that the earthquake hypocenters in Flores Area are dominated by the deep earthquake. The most earthquakes occur at depths of more than $100 \mathrm{~km}$. These results support the NTT BMKG report that the earthquake distribution in NTT is typically a tectonic earthquake caused by Indo-Australian plate laid.

The accuracy of hipocenter determination using hypo71 can be known from the residual value, the difference value between observation value and the value of calculation using trial solution which is use initial velocity model and travel time wave from hypocenter to station recorder. Hypocenter relocation using hypo71 yields a small residual between the observation time and calculation time indicated by RMS <1 that is shown in Figure 5. Hypocenter relocation using hypo71 yields a RMS $<1$ that is shown in Figure 5. this is indicating that there is larger amount of data which is have RMS between 0 up to 0.5 than data which is have RMS between 0.6 up to 1 . This shows the superiority of hypocenter relocation using hypo71.

\section{CONCLUSSION}

Hypocenter relocation using hypo71 generates the hypocenter earthquake in Flores region accumulated in certain blocks. The Northern part of Flores is dominated by very deep earthquakes associated with Flores Thrust Zone whereas in the South there are distribution shallow earthquakes to medium earthquake. 
SEBARAN GEMPA BUMI DI FLORES PERIODE 2010-2018

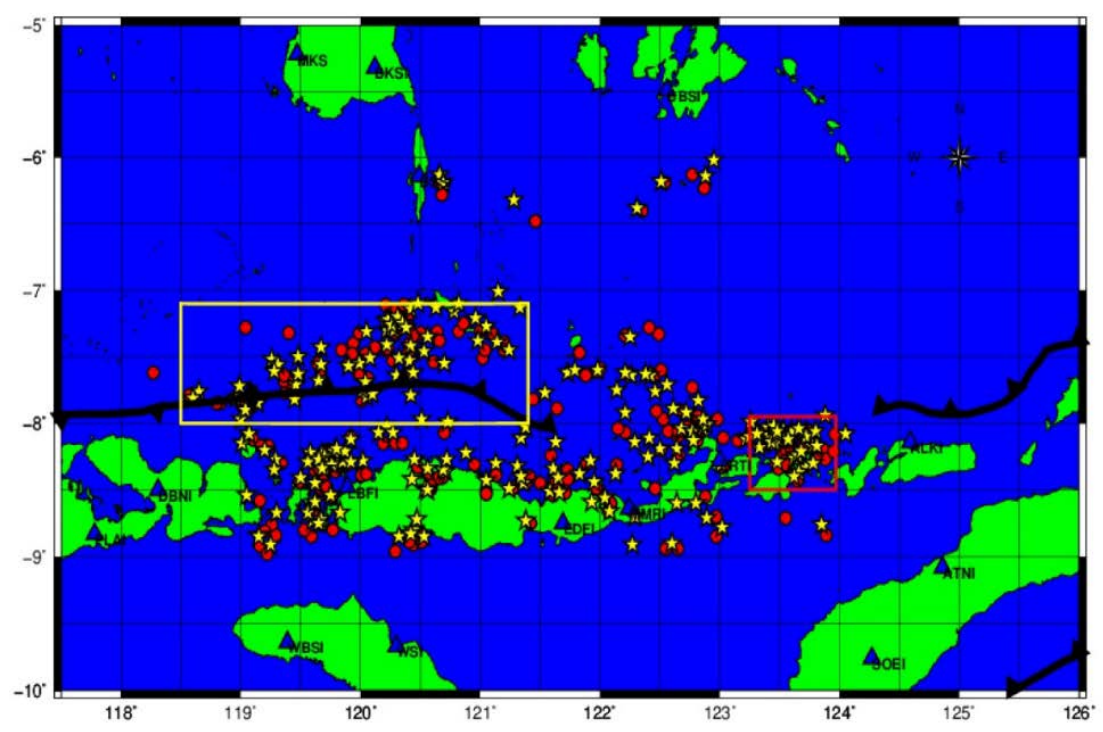

Figure 3. Distribution hypocenter before and after relocation using hypo71, the red circles, yellow stars, and blue triangles indicated hypocenter before relocation using Hypo71, after relocation and recorded stations, respectively.

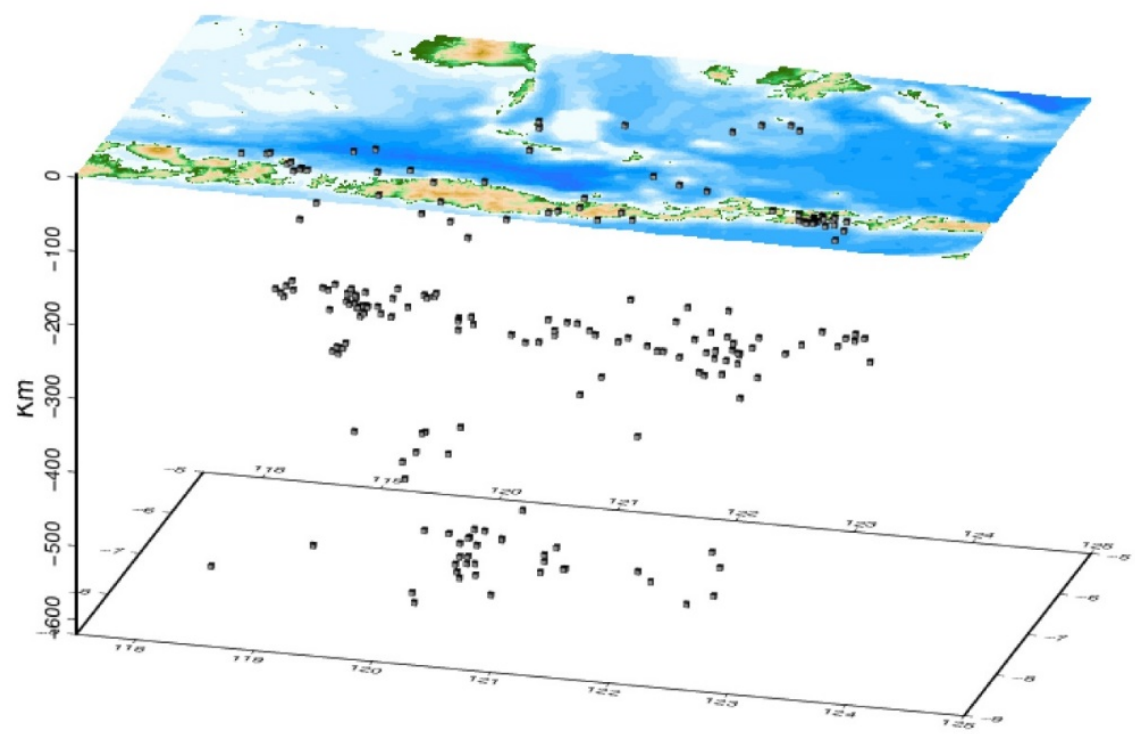

Figure 4. Position of hypocenter earthquake relocation result using hypo71 in 3D.

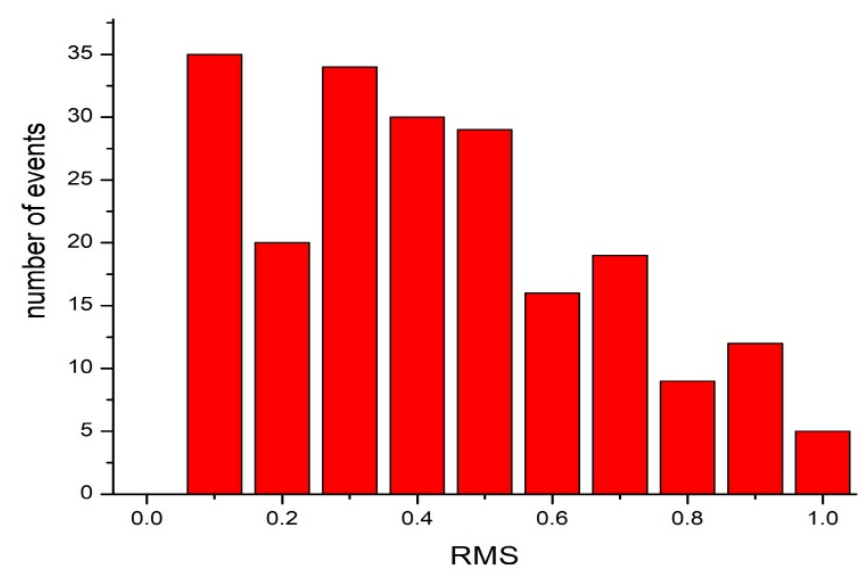

Figure 5. Histogram of relocation hypocenter RMS. 


\section{ACKNOWLEDGEMENTS}

Acknowledgements and appreciations are given to LPDP (Institute of Education Fund Management), Ministry of Finance of the Republic of Indonesia which has provided education and research funds, so this research can be done well.

\section{REFERENCES}

[1]

W. Hamilton and Geological Survey (États-Unis), "Earthquake map of the Indonesian region (Map).” Geological Survey, Dept. of the Interior, Washington, D.C, 1974.

[2] W. H. Lee and J. C. Lahr, "HYPO71 (revised; a computer program for determining hypocenter, magnitude, and first motion pattern of local earthquakes,” Menlo Park, California, 1975. 